\title{
EFFECTS OF INTERVENTION "HOPSPORT BRAIN BREAKS" PROGRAM ON PHYSICAL FITNESS AND SEDENTARY BEHAVIOUR IN PRIMARY SCHOOL
}

\author{
Laura Tumynaitė ${ }^{1}$, Brigita Miežienè $\dot{1}^{1}$ Magdalena Mo Ching Mok², Ming-kai Chin ${ }^{3}$, \\ Vitalija Putriūtė ${ }^{1}$, Virginija Rupainiene் ${ }^{4}$, Giedrè Stankevičienè $\dot{e}^{4}$, Arūnas Emeljanovas ${ }^{1}$ \\ Lithuanian Sports University ${ }^{l}$, Kaunas, Lithuania \\ The Hong Kong Institute of Education', Tai Pol, Hong Kong \\ HOPSports, Inc. ${ }^{3}$, Las Vegas, USA \\ Kaunas Panemune primary school ${ }^{4}$, Kaunas, Lithuania
}

\begin{abstract}
Background. Sedentary behaviour in children raise concern as the majority of children do not meet the healthrelated level of physical activity (PA) which is closely related with their physical fitness (PF). Digital facilities may help to solve the problem. Hypothesis. After the intervention "HOPSport Brain Breaks" physical fitness improves and sedentary behaviour decreases. The aim of the study was to assess the effects of "HOPSport Brain Breaks" video exercise intervention program on physical fitness and sedentary behaviour in a primary school.

Methods. The study included 113 primary schoolchildren from grades 1-4, among them there were 62 children in the experimental group and 51 in the control group (Mean age $=8.24, S D=1.10$ ). $\mathrm{PF}$ was assessed using the test battery (Fjortoft, Pedersen, Sigmundsson, \& Vereijken, 2011) pre- and post-intervention. Also passivity was measured twice using four questions from "Health Behaviour of School Children" questionnaire. The experimental group received Brain Breaks intervention every school day for three months in 5-9 min sessions during the breaks.

Results. After three months physical fitness (PF) did not improve, but sedentary behaviour reduced in the experimental group compared to the controls $(p<.05)$.

Conclusions. The results have shown that fun and enjoyment, which are the background of Brain Breaks intervention, were important factors in reducing sedentary behaviour. Studies also show that the level of PA is proportionally higher when children are given the opportunity to play active games and experience fun (Wickel et al., 2007). It may be concluded that Brain Breaks intervention program contributes to physical health of primary schoolchildren.
\end{abstract}

Keywords: primary schoolchildren, physical fitness, sedentary behaviour.

\section{INTRODUCTION}

B eing physically fit is not only a tribute to sports or physical education, but also the most significant factor of happier and more thoughtful life (Volbekiene \& Kavaliauskas, 2002). It might be said that the body structure and physiological functions of a physically fit person are in the best condition (United States Department of Health and Human services, 2008). Thus, physical fitness is a condition when a person does not get tired while working normally, i. e. he or she remains agile and feels good (Dreyer \& Hanson, 2008).

Most countries pay great attention to the workload, therefore, physical fitness is associated with functional capabilities to perform physical tasks without overworking. What is more, physical fitness is the result of physical activity, i.e. the best physical condition gained as a result of physical 
activity. As modern science claims about physical fitness, it is recognized as one of the most important health indicators. Furthermore, physical fitness is improved with the help of physical activity (Corbin et al., 2014).

It should be noted that the physical activity of children has decreased significantly during the last decades (Anderssen et al., 2006). Outdoor games have been replaced by physical activities indoors which require fewer physical attempts (Grund et al., 2000). Children more often are driven to school in a car or by bus than they go on foot or by bike. At the same time, participation in organized sports also decreases (Rice \& Howell, 2000). A discussion on possible consequences and recommendations how to change this evolving issue has been taking place in press, scientific articles, and among politicians for many years. However, the largest research on physical activity and physical fitness and their impact on health failed to find the required and specific results (Marshall \& Bouffard, 1997).

Sedentary behaviour is mostly defined as an act requiring low levels of energy expenditure while a person is sitting or lying (Katzmarzyk, 2010). Various markers of sedentary behaviour, like TV watching and using of computer, are associated with many chronic diseases (Chinapaw, Proper, Brug, van Mechelen, \& Singh, 2011). A lot of countries have generated public health guidelines that include recommendations on limiting presence in sedentary behaviour (Tremblay et al., 2011 a).

Recently studies have shown the increase in sedentary behaviour like TV watching etc. (Must, Barish, \& Bandini, 2009). Tremblay et al. (2011 b) state that TV watching for more than 2 hours in a day is closely related to reduced physical health. Sedentary behaviour may be associated with energy expenditure by, for instant, playing outside (de Craemer et al., 2012). This association provides a rationale for the development of interventions to decrease sedentary behaviour.

A rapid growth of popularity of new technologies and TV has been recognized as a significant contribution to the promotion of obesity (Proctor et al., 2003). Importantly, one of the solutions is the use of intervention video games at schools. Electronic games encourage children to be physically active using hands, feet or the whole body movements. These active electronic games depict movements of a wide variety of sports (football, basketball, boxing, martial arts, etc.) or other active actions performed in everyday life (window cleaning, dancing, etc.). An active video game is closely related to the reality, and while playing these video games, the results promote the development of habits of active daily activity (Maddison et al., 2001).

Certain recommendations on improving health through physical activity state that a child must be active for about 60 minutes a day (United States Department of Health and Human Services, Physical activity Guidelines for Americans, 2008). Children are receptive to innovations, therefore, they very quickly get used to a sedentary lifestyle, especially to computer, DVD games or TV. A new generation has improved the aforementioned information technology games and turned them to a method to promote physical activity of children. Previous studies have shown that interactive electronic games can significantly improve children's physical activity, using significantly more energy than sitting in one position and playing electronic games (Wang, Perry, 2006; Graves, Ridgers, \& Stratton, 2008).

Direct observation is not an exact measure of monitoring physical activity context; therefore, it is impossible to collect accurate data. This method has been used by many researchers in Hong Kong and America, so the research exactly shows just the scope of physical inactivity of children and how much of their leisure time is spent sedentarily (Sit, Lam, \& McKenzie, 2010). "HOPSport Brain Breaks" intervention program helps to develop certain movement habits integrated in games. "HOPSport Brain Breaks" intervention program is a simple, but effective way to solve the above mentioned problems. In case of extending the daily physical activity time, physical activity level would be significantly increased. There is a trend that the prolongation of time of daily physical activity and performance period is likely to result in the achievement of positive changes in physical fitness during the intervention period.

The aim of the study was to investigate the effects of providing Brain Breaks (BB) video lessons during the breaks on children's changes in physical fitness and sedentary behaviour during a three- month intervention program.

Hypothesis. After the intervention "HOPSport Brain Breaks", physical fitness improves and sedentary behaviour decreases.

\section{METHODS}

Procedure. The intervention program was implemented in September-November at a primary 
school in Kaunas during the fall semester of 2013. Two classes from grades 1, 2, 3 and 4 were selected: one class was the experimental one, while the other - the control one. Before implementing the program, physical fitness of children from all grades was tested. Videos of 5-9 minutes that help to improve physical fitness and reduce the inactivity were shown at least once a day, for the period of three months. The activity of watching the videos was coordinated by the class teacher. After the intervention program, physical inactivity of children was re-tested by a questionnaire survey, and physical fitness was determined with the help of tests of physical fitness.

Participants. Participants were 113 Ist-IVthgrade children (Mean age $=8.24, S D=1.10$ ) from one primary school in Kaunas. Children were divided into two groups: experimental (31 boys and 31 girls) and control (29 boys and 22 girls). A written consent of parents of each participant was obtained.

Measures. Physical fitness tests were performed according to the methodology of tests of Fjortoft et al. (2011), which were selected from other physical fitness tests. All these tests reflect the children's daily physical activity, i.e. jumping, shooting, climbing, and jogging. Moreover, these physical fitness tests are for 5-12-year-olds. All tests were performed without any warm-up.

The following 9 physical fitness tests were used to measure the physical fitness of children:

1. Standing broad jump (cm). A component of physical fitness - explosive power.

A child stands behind a line marked on the ground with feet slightly apart. The knees are bent, and arms are stretched ahead, parallel to the ground. By swinging the arms, the child takes off the land. The child attempts to jump as far as possible. The result is from take-off line to the point of contact on the land. The higher score indicates the better performance.

2. Jumping a distance of $\mathbf{7} \mathbf{m}$ on two feet as fast as possible (s). A component of physical fitness - muscle strength of legs.

A child jumps a distance of $7 \mathrm{~m}$ on two feet, as fast as possible. The result of subject (two attempts are made, the best is recorded) is the time needed to cross the distance of 7 $\mathrm{m}$ (measured in seconds). The lower score indicates the better performance.

3. Jumping a distance of $7 \mathrm{~m}$ on one foot (the child is free to choose which foot) as fast as possible (s). A component of physical fitness - muscle strength of legs.

A child jumps a distance of $7 \mathrm{~m}$ on one foot (the child is free to choose which foot), as fast as possible. The result of the child (two attempts are made, the best is recorded) is the time needed to cross the distance of $7 \mathrm{~m}$ (measured in seconds). The lower score indicates the better performance.

4. Throwing a tennis ball with one hand (m). A component of physical fitness - muscle strength of arms.

Throwing a tennis ball with one hand (the child chooses which hand) as far as possible. The right-handed child stands with the left foot at start line, while the left-handed one with right fo0ot. The result of child (two attempts are made, the best is recorded) is the distance thrown (from start line to ball falling point, measured in meters). The higher score indicates the better performance.

5. Pushing a medicine ball from chest (m). A component of physical fitness - muscle strength of arms.

It is pushing the medicine ball $(1 \mathrm{~kg})$ with two hands as far as possible. The starting position is with the feet parallel to each other and shoulder width apart, with the ball held against the chest. The result of the child (two attempts are made, the best is recorded) is the distance from the start line to the ball (measured in meters). The higher score indicates the better performance.

6. Climbing up wall bars (s). A component of physical fitness - coordination

Climbing up the wall bars (there must be 4 columns of wall bars). Climbing up the first column, crossing 2 columns to the right, and climbing down the fourth column as fast as possible is required. Each column of the wall bars is $2.55 \mathrm{~m}$ height and $0.75 \mathrm{~m}$ width. The result of a child (two attempts are made, the best is recorded) is the time, recorded as a child puts both feet on the ground (measured in seconds). The lower score indicates the better performance.

7. $10 \times 5$ m shuttle run (m). A component of physical fitness - agility

10 x $5 \mathrm{~m}$ shuttle run. Two parallel lines with the distance of 5 metres from each other are marked on the floor. The child stands behind the line and prepares to run. One foot must be very close to start line. The child runs to the 
finish line as fast as possible, and then comes back to the start line by overstepping it with both feet. It is one time, and there are 5 runs. When running for the fifth time, the child should not reduce his/her speed at the finish line. The result of a child (two attempts are made, the best is recorded) is the time recorded when start line is crossed at $5^{\text {th }}$ time (measured in seconds). The lower score indicates the better performance.

8. $20 \mathrm{~m}$ run (s). A component of physical fitness - speed.

Running $20 \mathrm{~m}$ as fast as possible from a standing position. It is attempted only once. If the child makes an error, the test is repeated. The result of child is the time required to run the distance of $20 \mathrm{~m}$ (measured in seconds). The lower score indicates the better performance.

9. 6 min run $(9 \times 18),(m)$. A component of physical fitness - endurance.

Reduced Cooper test. The child runs or walks around a marked rectangle (dimensions $9 \times 18$ $\mathrm{m}$ (volleyball field)) for 6 minutes. Both running and walking are allowed. The result of child the distance covered in 6 minutes (measured in meters).

The following materials were needed for administering the tests: masking tape, ruler, stop watch, tennis ball, medicine ball $(1 \mathrm{~kg})$, wall bars at least 4 columns wide, and gym mats. Tests were performed one after another, following the specified sequence. The higher score indicates the better performance.

Sedentary behaviour was assessed by the questionnaire Health Behaviour of School Children (HBSC). Outcome variables were the time spent for TV viewing and using a PC (weekday and weekend day).

Physical activity intervention "HOPSport Brain Breaks" is a set of videos of 2-10 minutes, based on physical activity during breaks. Videos have been initiated in Lithuania for the first time in collaboration with the Hong Kong Institute of Education which has successfully been supervising the project "HOPSport Brain Breaks" for some years, in partnership with 40 schools in 26 countries. Without any additional planning and preparations, teachers, with the help of information technologies, show one longer or two shorter videos in their class every day, during a break. Each video, the character of which is a real or animated instructor, demonstrates exercises which improve children's motor skills and practical abilities. The content of movies includes health knowledge and training in healthy nutrition, education of social skills, environmental management, and certain mathematics, writing skills, language, art, music and cultural knowledge. Online access to the official project web site: http://www.hopsports. com/content.php?pgID=289.

Statistical analysis. Statistical analysis was performed using SPSS for Windows 19.0 software (SPSS Inc., Chicago, USA). Descriptive statistics were used to describe the sample. Paired sample t-test was used to determine whether there is a significant difference between the average values of the same measurement made between two time points. Results were considered significant at $p<.05$.

\section{RESULTS}

Initially changes from the baseline to the follow-up in three months were evaluated in both control and experimental groups (results revealed performance in two physical fitness tests in the control group of girls after three months):

Pushing a medicine ball from chest $(\mathrm{m})$ and $10 \times 5 \mathrm{~m}$ shuttle run $(\mathrm{m})$ significantly $(p<.05)$ improved. Performance in other fitness tests did not change significantly. Standing broad jump (s), jumping distance of $7 \mathrm{~m}$ on one feet $(\mathrm{s} / 7 \mathrm{~m})$, jumping distance of $7 \mathrm{~m}$ on two feet $(\mathrm{s} / 7 \mathrm{~m}), 10 \times 5$ shuttle run (s), pushing a medicine ball $(1 \mathrm{~kg})$ with both hands (m), running $20 \mathrm{~m}$ (s), throwing tennis ball with one hand (m) (Figure1).

After three months, scores in standing long jump $(\mathrm{cm})$ increased, but scores in $10 \times 5 \mathrm{~m}$ shuttle run $(\mathrm{m})$ significantly $(p<.05)$ decreased and fitness worsened in the control group of boys. The performance in other fitness tests did not change significantly. Results of tanding broad jump (s), jumping distance of $7 \mathrm{~m}$ on one feet ( $\mathrm{s} / 7 \mathrm{~m}$ ), jumping distance of $7 \mathrm{~m}$ on two feet $(\mathrm{s} / 7 \mathrm{~m})$, climbing up wall bars (s), running $20 \mathrm{~m}(\mathrm{~s})$, throwing a tennis ball with one hand $(\mathrm{m})$ are given in Figure2.

In the experimental group of girls after three months of intervention, the scores in jumping a distance of $7 \mathrm{~m}$ on two feet (s) significantly $(p<.05)$ increased and muscle strength of leg fitness worsened, however, the scores of pushing a medicine ball from the chest $(\mathrm{m})$ increased and muscle strength of arm fitness improved. Results of standing broad jump (s), jumping distance of $7 \mathrm{~m}$ on one feet (s/7 m), $10 \times 5$ shuttle run (s), climbing up wall bars (s), running $20 \mathrm{~m}$ (s), throwing tennis ball with one hand (m) are given in Figure3. 


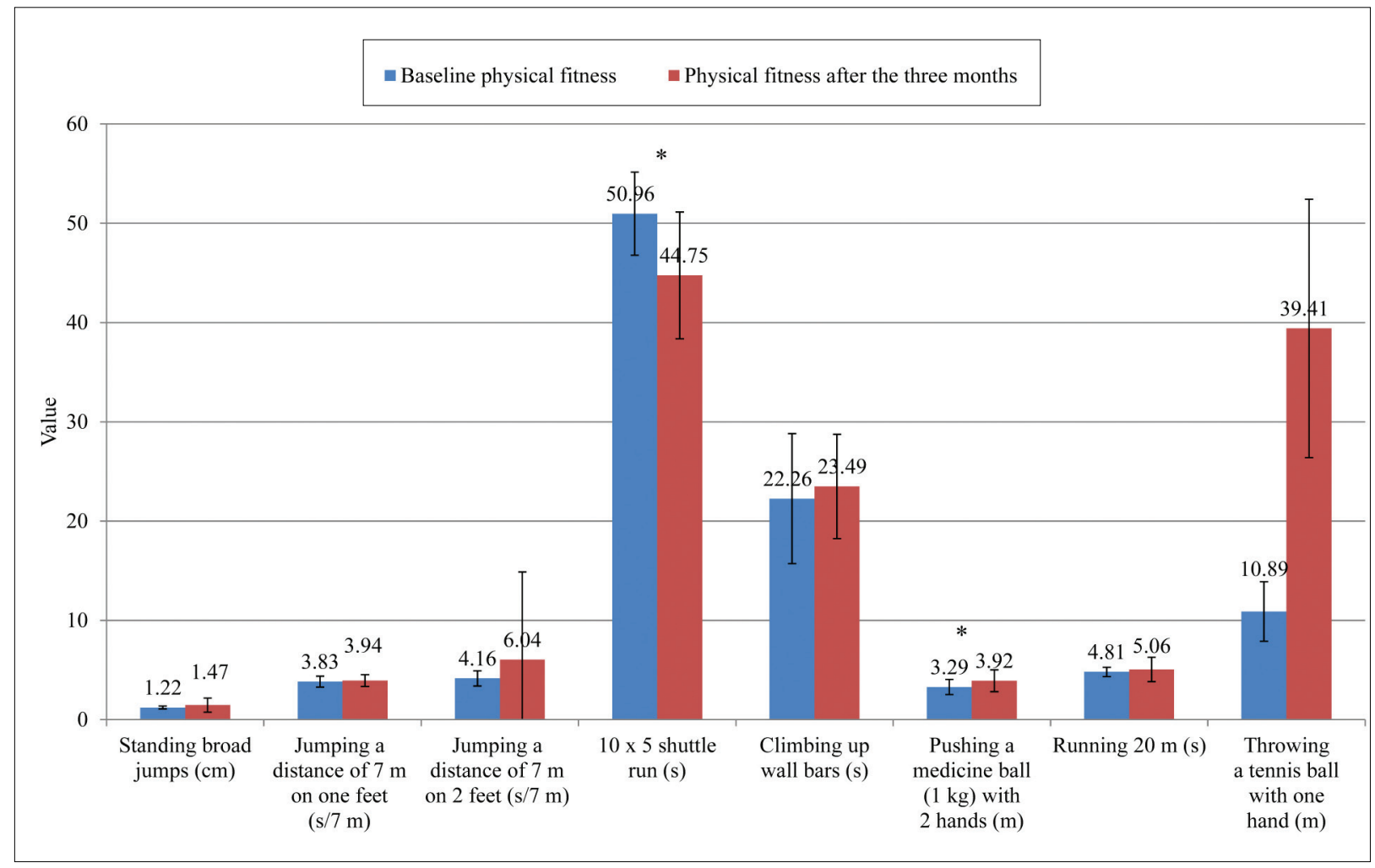

Note. $*-\mathrm{p}<.05$

Figure 1. Changes of physical fitness in three months in the control group of girls

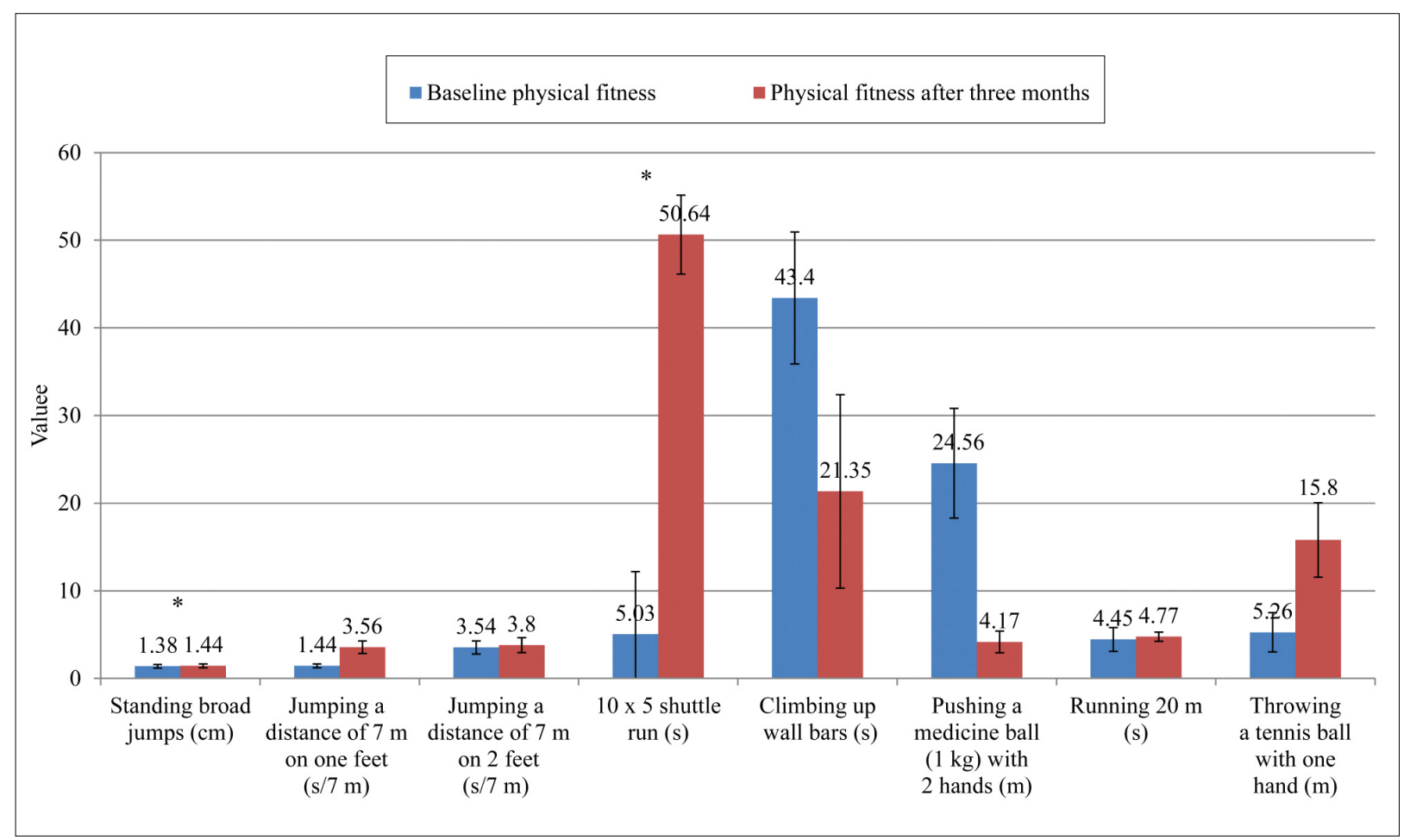

Note: ${ }^{*}-p<.05$

Figure 2. Changes of physical fitness in three months in the control group of boys

In the experimental group of boys, the scores in jumping a distance of $7 \mathrm{~m}$ on one foot (s) and climbing up wall bars (s) significantly $(p<.05)$ increased, respectively coordination fitness worsened, but performance in $10 \times 5 \mathrm{~m}$ shuttle run (m) test improved $(p<.05)$. Results of standing 
broad jump (s), jumping distance of $7 \mathrm{~m}$ on two feet $(\mathrm{s} / 7 \mathrm{~m})$, running $20 \mathrm{~m}(\mathrm{~s})$, and throwing a tennis ball with one hand (m) are given in in Figure 4.

Further changes in three months in sedentary behaviour were examined and presented in Figure
5. Results in the figure indicate that the control group significantly $(p<.05)$ increased watching TV time by 14 minutes on work days (Figure 5).

Meanwhile, the experimental group significantly reduced $(p<.05)$ all the sedentary behaviour forms:

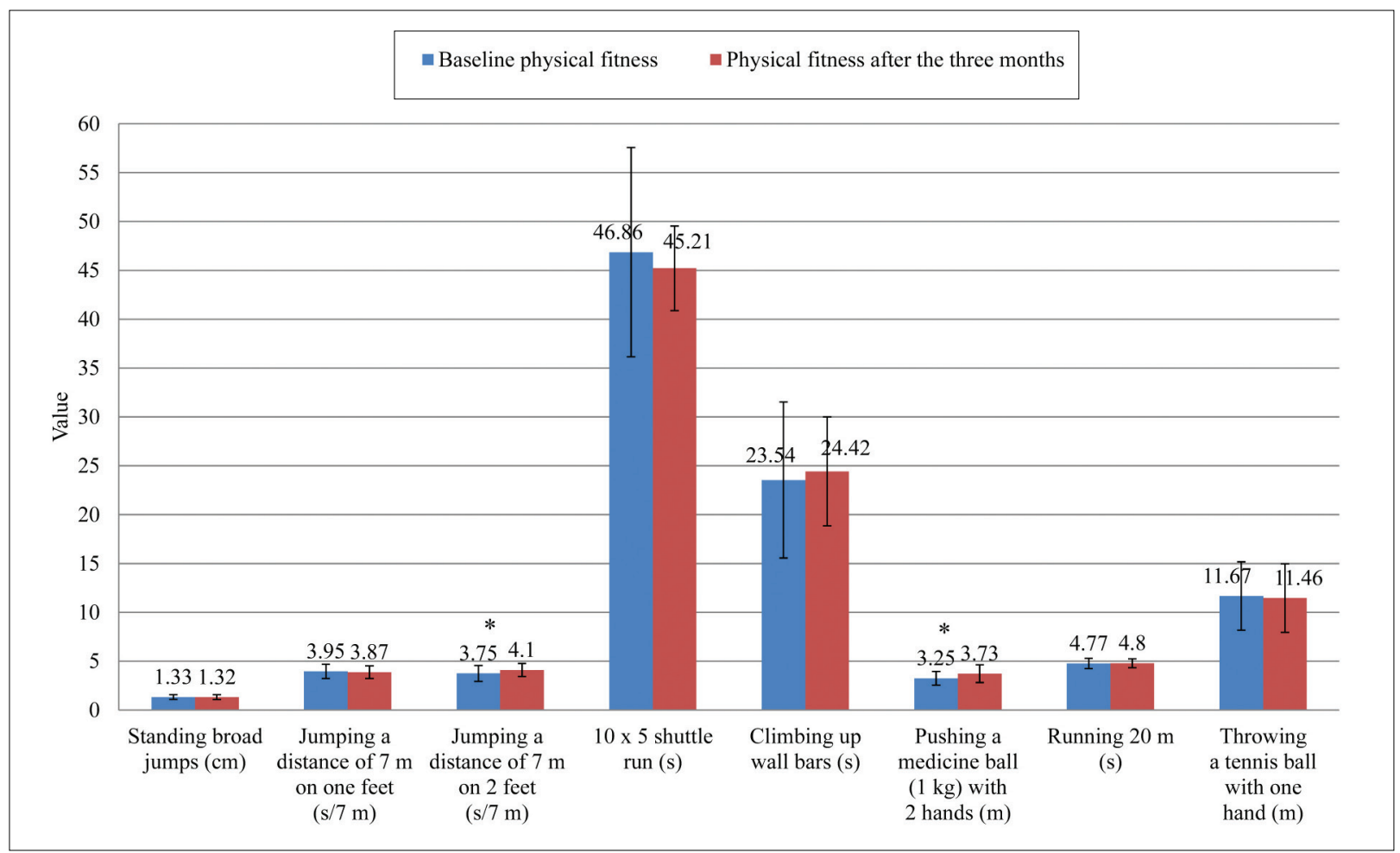

Note. $*-p<.05$

Figure 3. Changes of physical fitness in three months in the experimental group of girls

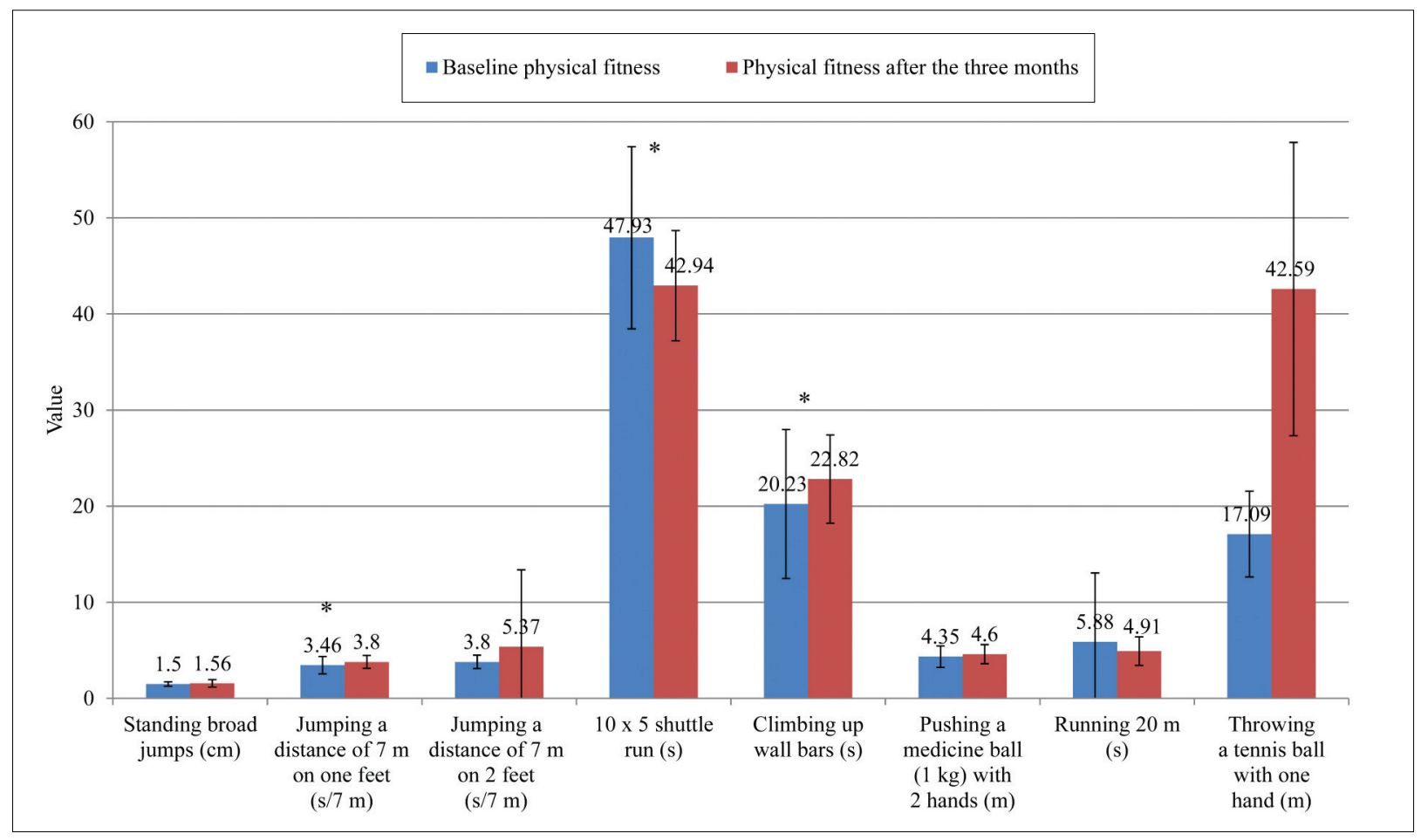

Note. $*-p<.05$.

Figure 4. Changes of physical fitness in three months in the experimental group of boys 
watching TV and using computer during the work days and at weekends. Watching TV during the work days decreased by 8 minutes, during the weekend - by 10 minutes, using computer during the work days decreased by 17 minutes, during the weekends - by 24 minutes (Figure 6).

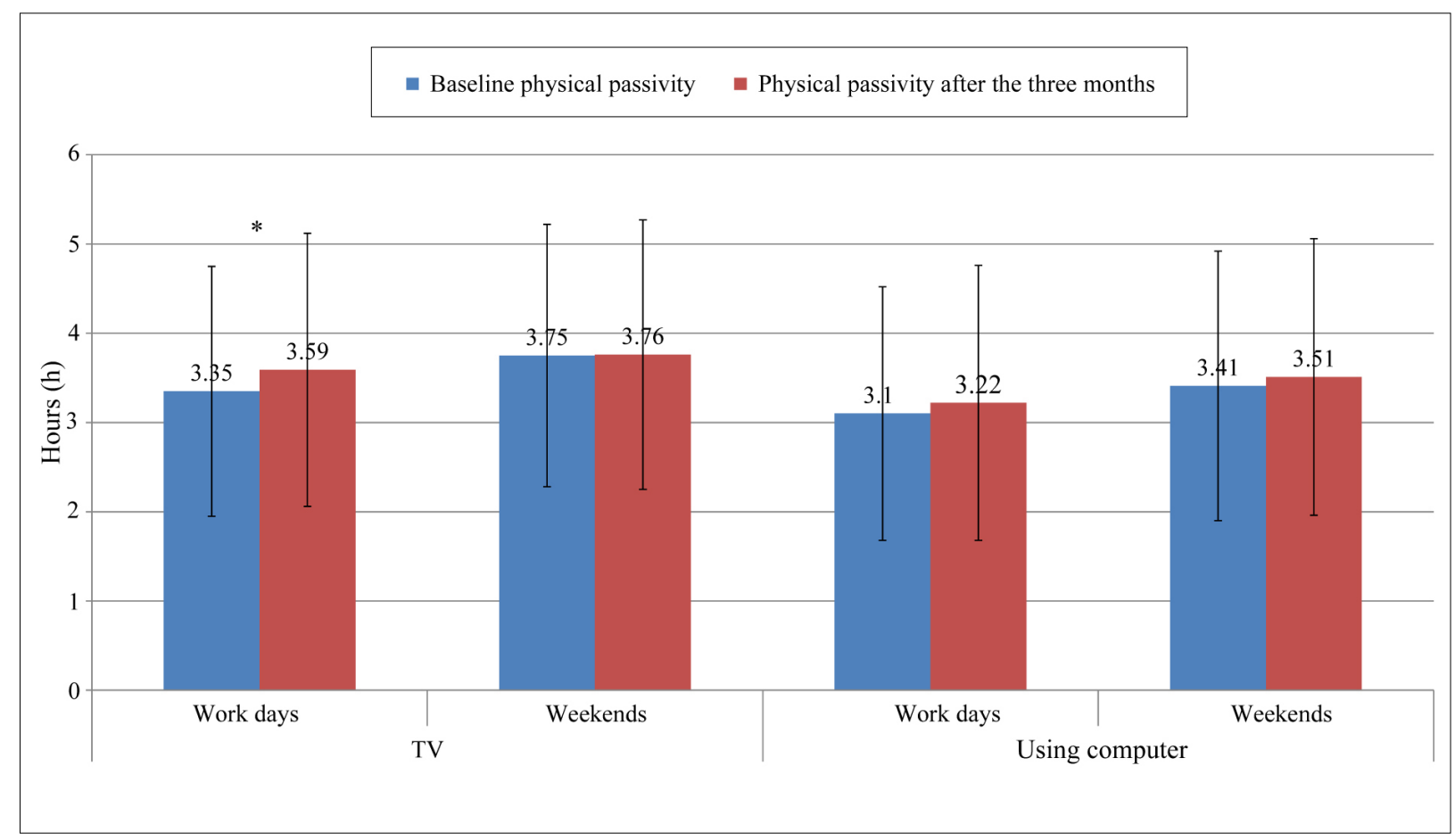

Note. $*-p<.05$.

Figure 5. Changes in the sedentary behaviour of the control group in three months' time

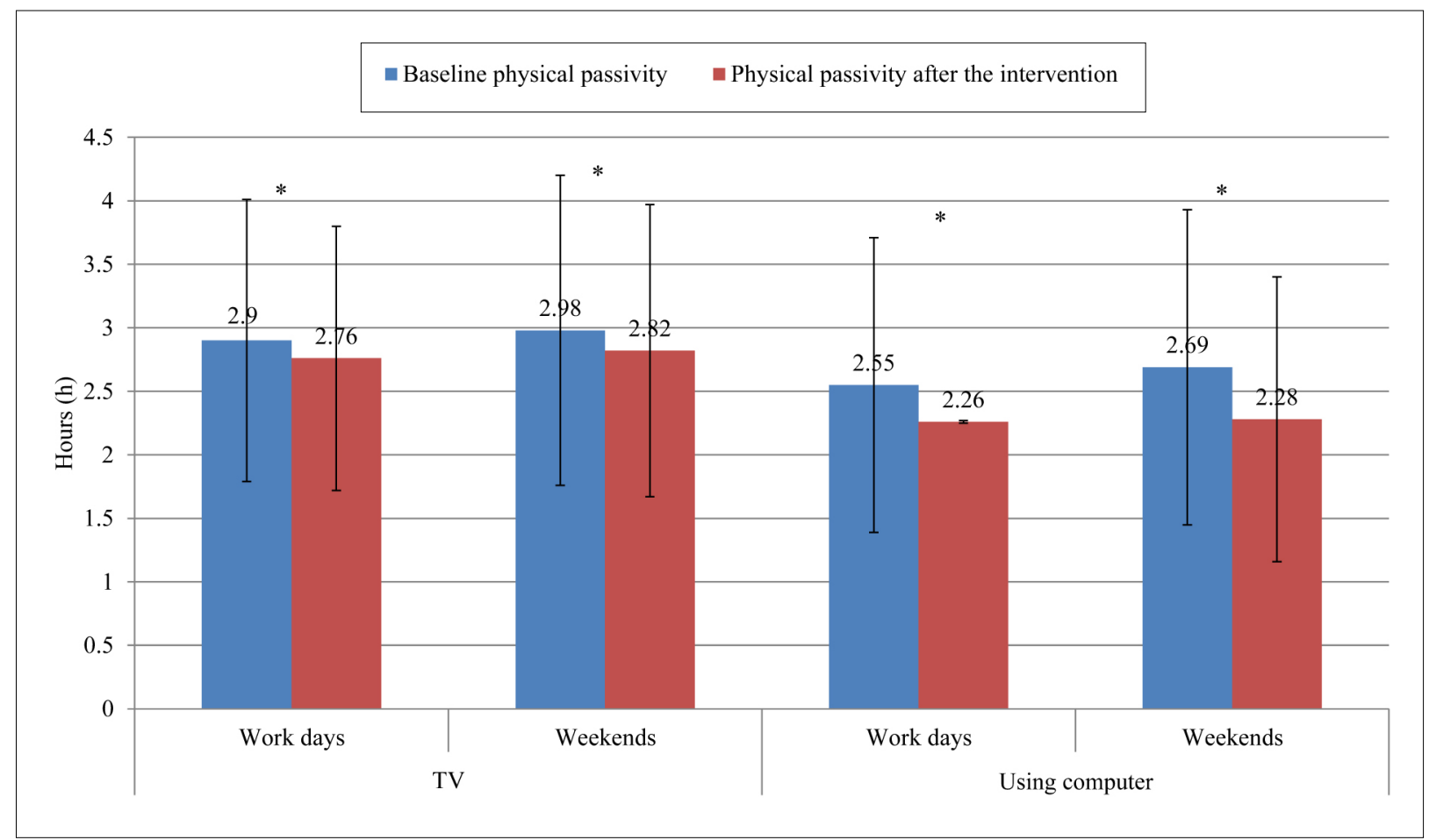

Note. $*-p<.05$.

Figure 6. Changes in the sedentary behaviour of the experimental group in three months' intervention period 


\section{DISCUSSION}

The general primary physical education programs maintain that physical activity is the key factor promoting the body to grow and develop. Each form of movement optimizes not only motor, but also mental and social maturity evolution of a human being. Primary schoolchildren are very receptive, agile, willing to know the world and themselves, therefore, at this age it is important to allow the children to experience the joy of movement, to encourage them to be physically active.

Following the research-based claims, Brazilian scientists argue that low physical fitness is determined by several factors (Hiraga et al., 2014): low physical activity, inaccurate perception of a person about his/her potential physical activity and its benefits, extremely high body mass index (BMI) indicators. HOPSport BB helps to develop certain movement habits with the help of the games. "HOPSport Brain Breaks" intervention program is a simple but effective way to solve the above mentioned problems. In case of extending the daily physical activity time, physical activity level would be significantly increased. There is a trend that the prolongation of time of daily physical activity and performance period is likely to result in the achievement of positive changes in physical fitness during the intervention period.

This research demonstrates that intervention of "HOPSport Brain Breaks" during the school breaks can successfully reduce sedentary behaviours among children (Steeves, Thompson, Bassett, Fitzhugh, \& Raynor, 2012).

Most of the previously applied programs promoting students' physical activity used to fail. The reasons for this include inappropriate structure, lack of financial resources or simply unattractiveness for children (Bundy et al., 2011). "HOPSport Brain Breaks" program is acceptable by its novelty, it is safe. There is no need for financial resources, and, what is particularly attractive to children, is presented by using information technologies. An increasingly growing interest of children in information technologies, which promote sedentary lifestyle, leads children to a wide range of diseases (cardiovascular, obesity, etc.). Frequent use of computers and watching TV can reduce certain physical skills, which are closely related to physical activity and are particularly necessary for normal development of motor skills (Straker et al., 2011). Therefore, this program has met the children's need of computer games and information technologies, at the same time encouraging the primary schoolchildren to move actively.

Skurvydas, Stonkus, and Volbekienè (2006) showed that certain skills start developing during the first year of child's learning, which needs wellcoordinated and quick movements. Endurance of 7-11-year-old child is not well developed; boys and girls' endurance increases significantly only in twelfth year; 7-8-year-old children are unable to regulate their actions adequately. They are unable to maintain the required rate of motions, feel the subtle changes of rhythm, distinguish and dose the muscle tension. However, all these important features are trained extensively. Most of the children in the experimental group are from the first and the second grades, i. e. 7-9 years old. Research conclusions demonstrate that children at this age do not regulate their movements effectively.

Certain recommendations for improving health through physical activity state that a child must be active for about 60 minutes a day (United States Department of Health and Human Services, 2008). Children are receptive to innovations, therefore, they very quickly get used to a sedentary lifestyle, especially to computer, DVD games or TV. A lot of research indicates that physical activity and fitness are closely related, however, children's daily activity fails to comply with the international recommendations (Strong et al., 2005). While analysing the results of completed research it was noted that that 10 minutes of physical activity a day, within the period of three months, is not enough to improve physical fitness of primary schoolchildren. The main recommendation, based on the international guidelines, is to extend the time of physical activity a day. Physical activity for 10 minutes a day, and doing so every day for more than 3 months, can introduce useful changes in physical activity and.

This research can be compared with previously carried out research on motivation of children which revealed that just spending the time, while being engaged in a favourite activity, without seeking to achieve the results, is an effective motivational aspect for children, which is closely related with higher physical activity level and gradually decreasing inactivity (Mackintosh, Knowles, Ridgers, \& Fairclough, 2011).

This research is unique in that it is based on not only the definition of physical activity, but also 
on other factors that are closely related to physical activity (motivation, knowledge about the benefits of physical activity and self-motivation to exercise). Videos not only improve certain motor skills, but also personal understanding about the benefits for children's health.

\section{CONCLUSIONS}

Three months' period of "HOPSport Brain Breaks" is not related to physical fitness of the primary schoolchildren. The results of physical fitness did not improve. The sedentary behaviour of primary schoolchildren reduced.

\section{ACKNOWLEDGEMENTS}

The authors gratefully acknowledge the contribution of all Panemunes Primary School staff, especially Kristina Jurskienè, Sonata Bružienè, Sandra Bernackienè, Vita Vedegienè for their assistance implementing Brain Breaks intervention program.

\section{REFERENCES}

Andersen, L. B., Harro, M., Sardinha, L. B., Froberg, K., Ekelund, U., Brage, S., \& Anderssen, S. A. (2006). Physical activity and clustered cardiovascular risk in children: A cross-sectional study (The European Youth Heart Study). Lancet, 368, 299-304. doi: 16860699

Bundy, A. C., Naughton, G., Tranter, P., Wyver, S., Baur, L., Schiller, W., ... Brentnall, J. (2011). The Sydney Playground Project: popping the bubblewrap unleashing the power of play: A cluster randomized controlled trial of a primary school playground-based intervention aiming to increase children's physical activity and social skills. BMC Public Health, 11, 680. doi:10.1186/1471-2458-11-680

Chinapaw, M. J, Proper, K. I, Brug, J., van Mechelen, W., \& Singh, A. S. (2011). Relationship between young peoples' sedentary behaviour and biomedical health indicators: A systematic review of prospective studies. Obesity Reviews, 12, e621-32. doi: 21438990

Corbin, C. B., Welk, G. J., Richardson, C., Vowell, C., Lambdin, D., \& Wikgren, S. (2014). Youth physical fitness: Ten key concepts. JOPERD: The Journal of Physical Education, 85(2), 8-24.

de Craemer, M., de Decker, E., de Bourdeaudhuij, I., Vereeker, C., Deforche, Y., ... Cardon, G. (2012). Correlates of energy balance-related behaviours in preschool children: A systematic review. Obesity Review,13, 13-28. doi: 10.1111/j.1467789X.2011.00941.x

Dreyer, G., \& Hanson, G. F. (2008). The assessment of physical fitness by correlation of vital capacity and certain measurements of the body. America: American Libraries Collection.

Fjortoft, I., Pedersen, A. V., Sigmundsson, H., \& Vereijken, B. (2011). Measuring physical fitness in children who are 5 to 12 years old with a test battery that is functional and easy to administer. Physical Therapy, 91(7), 1087-1095. doi: 10.2522/ptj.20090350

Graves, L. E. F., Ridgers, N. D., \& Stratton, G. (2008). The contribution of upper limb and total body movement to adolescents' energy expenditure whilst playing
Nintendo Wii. European Journal of Applied Physiology, 104(4), 617-623. doi: 10.1007/978-3-540-68168-7_63

Grund, A., Dilba, B., Forberger, K., Krause, H., Siewers, M., \& Rieckert, H. (2000). Relationships between physical activity, physical fitness, muscle strength and nutritional state in 5- to 11-year-old children. European Journal of Applied Physiology, 82, 425-438. doi: 10985597

Hiraga, C. Y., Higassiaraguti Rocha, P. R., de Castro Ferracioli, M., Traina Gama, D. \& Pellegrini, A. M. (2014). Physical fitness in children with probable development coordination disorder and normal body mass index. Brazilian Journal of Kineanthropometry \& Human Performance, 16(2), 1829. doi: http://dx.doi. org/10.5007/1980-0037.2014v16n2p182

Katzmarzyk, P. T. (2010). Physical activity, sedentary behavior, and health: Paradigm paralysis or paradigm shift? Diabetes, 59, 2717-2725. doi: 10.2337/db10-0822

Mackintosh, K. A., Knowles, Z. R., Ridgers, N. D., \& Fairclough, S. J. (2011). Using formative research to develop CHANGE!: A curriculum-based physical activity promoting intervention. BMC Public Health, 11, 831. doi:10.1186/1471-2458-11-831

Maddison, R., Foley L., Ni Mhurchu, C., Jiang, Y., Jull, A., Prapavessis, H., ... Rodgers, A. (2011). Effects of active video games on body composition: A randomized controlled trial. The American Journal of Clinical Nutrition, 94(1), 156-163. doi: 10.3945/ ajcn.110.009142

Marshall, J. D., \& Bouffard, M. (1997). The effects of quality daily physical education on movement competency in obese versus non-obese children. Adapted Physical Activity Quarterly, 14, 222-237.

Must, A., Barish, E. E., \& Bandini, L. G. (2009). Modifiable risk factors in relation to changes in BMI and fatness: What have we learned from prospective studies of school-aged children? International Journal of Obesity (London), 33, 705-715. doi: 10.1038/ ijo. 2009.60 
Proctor, M. H., Moore, L. L., Gao D., Cupples, L. A., Bradlee, M. L., Hood, M. Y., \& Ellison, R. C. (2003). Television viewing and change in body fat from preschool to early adolescence: The Framingham Children's Study. International Journal of Obesity and Related Metabolic Disorders, 27, 827-33. doi: 12821969

Rice, M. H., \& Howell, C. C. (2000) Measurement of physical activity, exercise, and physical fitness in children: Issues and concerns. Journal of Pediatric Nursing, 3, 148-156. doi: 10897552

Sit, C. H. P., Lam, J. W. K., \& McKenzie, T. L. (2010). Children's use of electronic games: Choices of game mode and challenge levels. International Journal of Pediatrics, 2010, 1-6. doi:10.1155/2010/218586

Skurvydas, A., Stonkus, S., \& Volbekienè, V. (2006). Küno kultūra. Kaunas: Aušra.

Steeves, J. A., Thompson, D. L., Bassett, D. R., Fitzhugh, E. C., \& Raynor, H. A. (2012). A review of different behavior modification strategies designed to reduce sedentary screen behaviors in children. Journal of Obesity, 2012. 379215. doi: 10.1155/2012/379215

Straker, L. M., Campbell, A. C., Jensen, L. M., Metcalf, D. R., Smith, A. J., Abbott, R. A., ... Piek, J. P. (2011). Rationale, design and methods for a randomised and controlled trial of the impact of virtual reality games on motor competence, physical activity, and mental health in children with developmental coordination disorder. BMC Public Health, 11, 654. doi:10.1186/14712458-11-654

Tremblay, M. S., LeBlanc, A. G., Janssen, I., Kho, M. E., Hicks, A., Murumets, K., ... Duggan, M. (2011a). Canadian sedentary behaviour guidelines for children and youth. Applied Physiology, Nutrition and Metabolism, 36, 59-64. doi:21326378.

Tremblay, M. S., LeBlanc, A. G., Kho, M. E., Saunders, T. J., Larouche, R., Colley, R.C., ... Gorber, S. C. (2011b). Systematic review of sedentary behaviour and health indicators in school-aged children and youth. International Journal of Bahavioral Nutrition and Physical Activity, 8, 98. doi: 10.1186/14795868-8-98

United States Department of Health and Human services. (2008). Retrieved from http://www.hhs.gov/ocr/office/ about/cj2008.pdf

Volbekienè, V., \& Kavaliauskas, S. (2002). Eurofitas. Vilnius: Lietuvos sporto informacijos centras.

Wang, X., \& Perry, A. C. (2006) Metabolic and physiologic responses to video game play in 7 - to 10-year-old boys. Archives of Pediatrics and Adolescent Medicine, 160(4), 411-415. doi: 16585487

Wickel, E. E., Eisenmann, C. J., Pangrazi, P. R., Graser, S. V., Raustorp, A., Tomson, L. M, \& Cuddihy, T. F. (2007). Do children take the same number of steps every day? American Journal of Human Biology, 19(4), 537547. doi: 10.1002/ajhb.20613 